\title{
pH-labile sheddable block copolymers by RAFT polymerization: Synthesis and potential use as siRNA conjugates
}

\author{
Xin Huang a, Sema Ilknur Sevimli ${ }^{\text {a }}$, Volga Bulmus ${ }^{\mathrm{a}, \mathrm{b}, *}$ \\ a Centre for Advanced Macromolecular Design, School of Biotechnology E Biomolecular Sciences, UNSW, Sydney, NSW 2052, Australia \\ ${ }^{\mathrm{b}}$ Department of Chemical Engineering, Biotechnology and Bioengineering Graduate Program, Izmir Institute of Technology, Izmir 35430, Turkey
}

\section{A R T I C L E I N F O}

\section{Article history:}

Received 28 February 2013

Accepted 27 March 2013

Available online 16 April 2013

\section{Keywords:}

RAFT polymerization

Block copolymer

pH-labile

Drug delivery

siRNA delivery

Bioconjugate

\begin{abstract}
A B S T R A C T
Well-defined amphiphilic block copolymers composed of hydrophilic and hydrophobic blocks linked through an acid-labile acetal bond were synthesized directly by RAFT polymerization using a new poly(ethylene glycol) (PEG) macroRAFT agent modified with an acid-labile group at its R-terminal. The new macroRAFT agent was used for polymerization of poly(t-butyl methacrylate) (PtBMA) or poly(cholesterol-methacrylate) (PCMA) to synthesize well-defined block copolymers with a PEG block sheddable under acidic conditions. The chain extension polymerization kinetics showed known traits of RAFT polymerization. The molecular weight distributions of the copolymers prepared using the new macroRAFT agent remained below 1.2 during the polymerizations and the molecular weight of the copolymers was linearly proportional to monomer conversions. The acidcatalyzed hydrolysis behavior of the PEG-macroRAFT agent and the PEG- $b$-PtBMA ( $\mathrm{Mn}=13,600$ by GPC, PDI $=1.10$ ) was studied by GPC, ${ }^{1} \mathrm{H}$ NMR and UV-vis spectroscopy. The half-life of acid-hydrolysis was $70 \mathrm{~min}$ at $\mathrm{pH} 2.2$ and $92 \mathrm{~h}$ at $\mathrm{pH} 4.0$. The potential use of the $\mathrm{pH}$-labile shedding behavior of the copolymers was demonstrated by conjugating a thiol-modified siRNA to $\omega$-pyridyldisulfide modified PEG- $b$-PCMA. The resultant PEG- $b$ PCMA- $b$-siRNA triblock modular polymer released PCMA- $b$-siRNA segment in acidic and siRNA segment in reductive conditions, as confirmed by polyacrylamide gel electrophoresis.
\end{abstract}

(c) 2013 Elsevier Ltd. All rights reserved.

\section{Introduction}

pH-responsive soluble carriers have been extensively investigated for drug and gene delivery because of the $\mathrm{pH}$ gradients that exist in both normal and pathological conditions [1-22]. For example, some tumors [23] and inflammatory tissues [24] have are more acidic than the blood and normal tissue. In addition, although the endocytic pathway of cells begins near the physiological $\mathrm{pH}$ of 7.4, it drops to a lower $\mathrm{pH}$ of 5.5-6.0 in endosomes and approaches to $\mathrm{pH}$ 4.5-5.0 in lysosomes [25]. Based on this physiological

\footnotetext{
* Corresponding author at: Department of Chemical Engineering, Biotechnology and Bioengineering Graduate Program, Izmir Institute of Technology, Izmir 35430, Turkey.

E-mail address: volgabulmus@iyte.edu.tr (V. Bulmus).
}

trigger, the acid-labile polymers are potentially applicable for constructing drug/gene delivery systems that are triggered to function at acidic sites.

Recently, virus-mimetic polymeric carriers responding to the $\mathrm{pH}$ gradients at intracellular sites have been developed for intracellular drug delivery [4,15,26-28]. Hoffman, Stayton et al. were first to report "bioinspired encrypted polymers" [15]. These polymers synthesized by free radical copolymerization of hydrophobic monomers and subsequent PEG grafting, had an acid-labile PEG mask on the hydropbobic polymer backbone and were efficient in delivering peptides and antisense oligonucleotides into the cytoplasm of cells upon dePEGylation of the hydrophobic backbone [15]. In recent years, a number of pH-labile dynamic carriers adopting similar "dePEGylation" strategies 
have been developed, in general by modification of preready polymers, for intracellular delivery of genes and siRNA [7,8,29-35]. More recently, Lin et al. reported the in situ synthesis of a block copolymer that employed the pH-dependent dePEGylation strategy, by atom transfer radical polymerization [36]. This block copolymer consisted of poly(ethylene glycol) and poly(2-(dimethylamino)ethyl methacrylate) segments connected through an acid-labile cyclic ortho ester linkage was prepared directly from an ortho ester group-modified PEG-based ATRP initiator synthesized in five-steps.

Considering the value of $\mathrm{pH}$-dependent dePEGylation strategy for drug delivery applications, we have developed a reversible-addition fragmentation chain transfer (RAFT) polymerization-based method for in situ synthesis of well-defined pH-labile sheddable block copolymers to improve the applicability of the dePEGylation strategy in drug delivery. The RAFT technique is a powerful tool for synthesis of controlled architectures of a wide-variety of polymers with defined end- and pendant-functionalities, controlled molecular weights and narrow polydispersities using mild conditions (such as aqueous solutions and room temperatures) [37-41].

Herein, a new PEG-macroRAFT agent having an R-group containing acid-labile acetal bond was first synthesized. The pH-dependent hydrolysis of the PEG-macroRAFT agent was characterized by NMR. The block copolymers of PEG with methylmethacrylate, t-butylmethacrylate (tBMA) or cholesterol methacrylate (CMA) were synthesized via chain-extension copolymerization using the new PEGmacroRAFT agent. The potential use of the pH-labile macroRAFT agent strategy in drug/gene delivery was demonstrated by preparing reversible micelles of amphiphilic PEG- $b$-PtBMA diblock copolymers as potential drug carrier systems [42-45] and also modular PEG- $b$-PCMA- $b$-siRNA triblock copolymers as potential gene delivery systems $[46,47]$. The micelles formed from pH-labile PEG- $b$ $\mathrm{P}(\mathrm{tBMA})$ copolymers were dePEGylated in response to acidic environment, as determined by UV-vis spectroscopy. The modular triblock copolymers of siRNA released PCMA- $b$-siRNA and siRNA segments under acidic and reductive conditions, respectively, as determined by gel electrophoresis.

\section{Experimental section}

\subsection{Materials}

The initiator, 2,2-azobisisobutyronitrile (AIBN), was recrystallized twice from methanol prior to use. Poly(ethylene glycol) methyl ether (PEG5000, number-average molecular weight Mn $5000 \mathrm{~g} / \mathrm{mol}$ ), 4-formylbenzoic acid, 1,1,1-tris(hydroxymethyl)ethane (tHME), $3 \AA$ molecular sieve and p-toluenesulfonic acid monohydrate (PTSA) were purchased from Sigma-Aldrich (Australia) and dried in the vacuum oven prior to use. Methyl methacrylate (MMA) (Aldrich, 99\%), tert-butyl methacrylate (tBMA) (Aldrich, 98\%), poly(ethylene glycol) methyl ether acrylate (PEG-A) (Aldrich, Mn $480 \mathrm{~g} / \mathrm{mol}$ ) were purified via basic alumina gel column chromatography before use. N,N'-Dicyclohexyl- carbodiimide (DCC), 4-(dimethylamino)pyridine (DMAP), triethyl amine (TEA) and methacryloyl chloride were purchased from Sigma-Aldrich and used without further purification. Tetrahydrofuran (THF) was dried by refluxing with sodium metal. Acetonitrile, diethyl ether, and dichloromethane (Univar, analytical grade reagent) were used as received. 4-(Cyanopentanoic acid)-4-dithiobenzoate (CPADB) was synthesized according to the procedure described in the literature [37]. Cholesterol was purchased from Sigma-Aldrich. Cholesterol methacrylate monomer (CMA) was synthesized according to the procedure described elsewhere [48,49]. 5'-Sense strand thiol-modified siRNA (Sense strand: 5'ThioMC6 D GCU GAC CCU GAA GUU CAU CUU 3'; Antisense strand: 5' GAU GAA CUU CAG GGU CAG CUU 3') was purchased from IDT DNA.

\subsubsection{Synthesis of PEG formyl benzoic acid ester (1)}

PEG5000 (5 g, $1 \mathrm{mmol}$ ) and 4-formylbenzoic acid $(0.75 \mathrm{~g}, 5 \mathrm{mmol})$ were dissolved in a mixture of dichloromethane/THF $(30 \mathrm{~mL} / 30 \mathrm{~mL})$, and the resulting solution was stirred in an ice bath. DCC (206 mg, $1 \mathrm{mmol}$ ) and DMAP (12 mg, $0.1 \mathrm{mmol}$ ) were then added to the reaction solution. The solution was kept stirred overnight. Sedimentation was removed by filtration, and the solvent was removed under reduced pressure. The mixture was purified by precipitating in cold diethyl ether three times. After drying in vacuum oven, a white solid was obtained (3.82 g, yield 72.7\%). ${ }^{1} \mathrm{H}$ NMR (300 MHz, $\mathrm{CDCl}_{3}, \delta \mathrm{ppm}$ ): $10.05(1 \mathrm{H}, \mathrm{s},-\mathrm{CHO}), 8.12-7.95(4 \mathrm{H}, \mathrm{m}$, phenyl group), 4.5 $\left(2 \mathrm{H}, \mathrm{t},-\mathrm{CH}_{2} \mathrm{CH}_{2} \mathrm{OOC}\right), 3.8\left(\mathrm{H}, \mathrm{m},-\mathrm{OCH}_{2} \mathrm{CH}_{2} \mathrm{O}\right), 3.2(3 \mathrm{H}, \mathrm{s}$, $-\mathrm{OCH}_{3}$ ). The spectrum was shown in Fig. S1 (Supporting Information).

\subsubsection{Synthesis of PEG formyl benzoic acid ester 1,1,1- tris(hydroxymethyl)ethane acetal (2)}

All the glasswares and chemicals were dried prior to use. A mixture of $\mathbf{1}(0.522 \mathrm{~g}, 0.1 \mathrm{mmol}), 3$ Å molecular sieve (1 g), 1,1,1-tris(hydroxymethyl)ethane (tHME) (120 mg, $1 \mathrm{mmol}$ ), anhydrous PTSA (6.9 mg, $0.038 \mathrm{mmol}$ ), and anhydrous THF $(10 \mathrm{~mL})$ were heated to reflux for $8 \mathrm{~h}$, and cooled to ambient temperature. TEA was then added to quench the reaction. The solvent was removed under reduced pressure, and crude product was precipitated in cold ether twice to give white powder (2), yield $80 \% .{ }^{1} \mathrm{H}$ NMR (300 MHz, $\left.\mathrm{CDCl}_{3}, \delta \mathrm{ppm}\right): 8.12-7.6(4 \mathrm{H}, \mathrm{m}$, phenyl group), $5.42(1 \mathrm{H}, \mathrm{s}$, -phenyl $\mathrm{CHO}(\mathrm{O})), 4.5\left(2 \mathrm{H}, \mathrm{t},-\mathrm{CH}_{2} \mathrm{CH}_{2} \mathrm{OOC}\right), 3.8$ $\left(\mathrm{H}, \mathrm{m},-\mathrm{OCH}_{2} \mathrm{CH}_{2} \mathrm{O}\right), 3.2\left(3 \mathrm{H}, \mathrm{s},-\mathrm{OCH}_{3}\right)$. The spectrum is shown in Fig. S2 (Supporting Information).

\subsubsection{Synthesis of acid labile PEG-macroRAFT agent (3)}

Compound 2 (523 $\mathrm{mg}, 0.1 \mathrm{mmol}$ ) was dissolved in $30 \mathrm{~mL}$ of dichloromethane, and the solution was stirred in an ice bath. DCC (103 mg, $0.5 \mathrm{mmol}$ ), DMAP (12 mg, $0.1 \mathrm{mmol}$ ) and CPADB (140 $\mathrm{mg}, 0.5 \mathrm{mmol}$ ) were then added, and the solution was kept stirred overnight. Sedimentation was removed by filtering, and the solvent was removed under reduced pressure. The crude product was purified by precipitation in cold diethyl ether three times. After drying in a vacuum oven, a pink solid was obtained (yield 52.7\%). ${ }^{1} \mathrm{H} \quad \mathrm{NMR} \quad\left(300 \mathrm{MHz}, \mathrm{CDCl}_{3}, \delta \mathrm{ppm}\right)$ : 8.12-7.25 (9H, m, phenyl group), $5.42(1 \mathrm{H}, \mathrm{s},-$ phenyl 
$\mathrm{CH}(\mathrm{O}) \mathrm{O}), 4.5\left(2 \mathrm{H}, \mathrm{t},-\mathrm{CH}_{2} \mathrm{CH}_{2} \mathrm{OOC}\right), 4.39\left(2 \mathrm{H}, \mathrm{s},-\mathrm{CCH}_{2} \mathrm{O}\right), 3.8$ $\left(\mathrm{H}, \mathrm{m},-\mathrm{OCH}_{2} \mathrm{CH}_{2} \mathrm{O}\right), 3.2\left(3 \mathrm{H}, \mathrm{s},-\mathrm{OCH}_{3}\right), 2.7-2.35(4 \mathrm{H}, \mathrm{m}$, $\left.\mathrm{OCCH}_{2} \mathrm{CH}_{2} \mathrm{C}\left(\mathrm{CH}_{3}\right) \mathrm{CN}\right), 1.98$ (3H, s, $\left.\mathrm{CH}_{3} \mathrm{CCN}\right)$.

\subsubsection{RAFT polymerizations}

A number of polymerizations with methyl methacrylate (MMA), tert-butyl methacrylate (tBMA), poly(ethylene glycol acrylate) (PEG-A) and cholesterol methacrylate (CMA) were performed using the acid labile PEG-macroRAFT agent 3. The monomer concentration and the ratio of the monomer, RAFT, and initiator concentrations were varied as tabulated in Table 1. A typical procedure is given below for polymerization of t-butyl methacrylate: $55.0 \mathrm{mg}$ $(0.01 \mathrm{mmol})$ of the RAFT agent $3,284 \mathrm{mg}(2 \mathrm{mmol})$ of tert-butyl methacrylate, $0.33 \mathrm{mg}(0.002 \mathrm{mmol})$ of AIBN were dissolved in $2.1 \mathrm{~mL}$ of acetonitrile. Following the sealing of the vial with rubber septum, the polymerization solution was purged with nitrogen for $30 \mathrm{~min}$ in an ice bath. The solution was placed in an oil bath at $65^{\circ} \mathrm{C}$. Aliquots $(0.1 \mathrm{~mL})$ were taken at predetermined time intervals and quenched via rapid cooling and exposure to oxygen. For each sample, the number-average molecular weight $(\mathrm{Mn})$ and polydispersity index (PDI) were determined by GPC without purification. The conversions were determined from the ${ }^{1} \mathrm{H}$ NMR spectra by comparison of the integrations of the vinyl proton peaks of the monomer and the methyl protons in the polymer. The polymer was concentrated by partial evaporation of acetonitrile, and dialyzed against acetone for 2 days to remove unreacted monomer and the RAFT agent. After removing the solvent and drying in vacuum oven for $24 \mathrm{~h}$, the samples were further analyzed by GPC and ${ }^{1} \mathrm{H}$ NMR.

2.1.5. Synthesis of $\omega$-pyridyl-disulfide functional polymer by aminolysis in the presence of 2,2'-dithiodipyridine

$50 \mathrm{mg}$ of PEG- $b$-Poly(cholesterol methacrylate) (PEG- $b$ PCMA $)\left(7.76 \times 10^{-6} \mathrm{~mol}, \mathrm{Mn}=6442 \mathrm{~g} / \mathrm{mol}\right.$ by NMR, $7230 \mathrm{~g} / \mathrm{mol}$ and PDI $=1.12$ by GPC) and $33 \mathrm{mg}$ of $2,2^{\prime}$-dithiodipyridine (DTP) $\left(1.51 \times 10^{-4} \mathrm{~mol}\right)$ were dissolved in acetonitrile $(2 \mathrm{~mL})$. The solution was purged for $30 \mathrm{~min}$ with nitrogen to remove the oxygen. Hexylamine $(5 \mu \mathrm{L}$, $3.77 \times 10^{-5} \mathrm{~mol}$ ) was then added under nitrogen. The solution was shaken for $5 \mathrm{~h}$, and the color was observed to change from pink to yellow. The polymer was dialyzed (MWCO $=3500 \mathrm{Da}$ ) against an acetone/water mixture (50/50 V\%) for 2 days to remove the excess of DTP, and dialyzed against water for 1 day to remove acetone. The final polymer was freeze-dried and analyzed by ${ }^{1} \mathrm{H}$ NMR.

\subsubsection{Conjugation of siRNA to $\omega$-pyridyl-disulfide functional (PEG-b-PCMA)}

$5^{\prime}$-Sense strand thiol-modified siRNA $(2 \mu \mathrm{L}, 0.5 \mathrm{mM}$ in RNAse free water) was mixed with DTT ( $5 \mu \mathrm{L}, 200 \mathrm{mM})$ solution and kept for $3 \mathrm{~h}$ at room temperature. To remove unreacted DTT, siRNA was precipitated using a large quantity of ethanol. The siRNA pellet was completely resuspended in $30 \mu \mathrm{L}$ of $\omega$-pyridyl-disulfide-(PEG- $b$-PCMA) solution $(50 \mathrm{mg} / \mathrm{mL}$, in $100 \mathrm{mM}$ sodium bicarbonate buffer at $\mathrm{pH} 8.5$ ) and left at room temperature for $20 \mathrm{~h}$ before assessing the conjugation by polyacrylamide gel electrophoresis (PAGE).

\subsection{Instrumental analyses}

\subsubsection{Nuclear magnetic resonance (NMR) spectroscopy}

${ }^{1} \mathrm{H}$ NMR and ${ }^{13} \mathrm{C}$ NMR analyses were performed using a Bruker 300-MHz spectrometer. Deuterated solvents $\left(\mathrm{CDCl}_{3}, \mathrm{D}_{2} \mathrm{O}\right)$ were purchased from Sigma-Aldrich. Sample preparation was performed by dissolving $10 \mathrm{mg}$ (for ${ }^{1} \mathrm{H}$ NMR) and $100 \mathrm{mg}$ (for ${ }^{13} \mathrm{C} \mathrm{NMR}$ ) of sample in $600 \mu \mathrm{L}$ of deuterated solvent.

The hydrolysis kinetic analyses were performed at $\mathrm{pH}$ $2.2,3.0$ and 4.0 buffer solutions prepared in $\mathrm{D}_{2} \mathrm{O}$. Citratephosphate buffer solution (200 mM, pH 3.0 and 4.0) and acetic acid buffer solution $\mathrm{pH} 2.2$ were first prepared, and $600 \mu \mathrm{L}$ of each buffer was freeze-dried. The dried salts were dissolved in $600 \mu \mathrm{L}$ of $\mathrm{D}_{2} \mathrm{O}$ to obtain buffer solutions in $\mathrm{D}_{2} \mathrm{O}$. After mixing the polymer precursor $\mathbf{2}$ in the NMR tube, the ${ }^{1} \mathrm{H}$ MNR detection was performed immediately. The proton signals were collected at every $15 \mathrm{~min}$ ( $\mathrm{ns}=16$ times).

\subsubsection{Gel permeation chromatography (GPC)}

GPC analyses were performed using tetrahydrofuran (THF)/0.05 mol\% lithium bromide (LiBr) or N,N-dimethylacetamide (DMAC)/0.05 mol\% $\mathrm{LiBr}$ as the mobile phase.

Table 1

Polymerization of various monomers mediated by PEG-macroRAFT agent $\mathbf{3}$ under different conditions. In all polymerizations the monomer concentration and temperature were $1 \mathrm{M}$ and $65^{\circ} \mathrm{C}$, respectively.

\begin{tabular}{|c|c|c|c|c|c|c|c|}
\hline \multirow[t]{2}{*}{ Entry } & \multirow[t]{2}{*}{ Monomer } & \multirow[t]{2}{*}[\mathrm{M}]{$/[\mathrm{RAFT}] /[\mathrm{I}]^{\mathrm{a}}$} & \multirow[t]{2}{*}{ Time (h) } & \multirow[t]{2}{*}{ Conv $^{\mathrm{b}}(\%)$} & \multicolumn{2}{|c|}{$\mathrm{Mn}(\mathrm{g} / \mathrm{mol})$} & \multirow[t]{2}{*}{$\mathrm{PDI}^{\mathrm{e}}$} \\
\hline & & & & & Thero $^{\mathrm{c}}$ & $\mathrm{GPC}^{\mathrm{d}}$ & \\
\hline 1 & MMA & $200 / 1 / 0.2$ & 10 & 40 & 13,496 & 14,500 & 1.12 \\
\hline 2 & tBMA & $200 / 1 / 0.2$ & 10 & 30 & 14,016 & 13,600 & 1.10 \\
\hline 3 & tBMA & $200 / 1 / 0.2$ & 24 & 75 & 26,796 & 28,400 & 1.25 \\
\hline 4 & CMA & $30 / 1 / 0.2$ & 15 & 18 & 7953 & 9100 & 1.12 \\
\hline 5 & CMA & $17 / 1 / 0.2$ & 15 & 15 & 6656 & 7200 & 1.12 \\
\hline 6 & PEG-A & $50 / 1 / 0.2$ & 8 & 35 & 13,800 & 14,000 & 1.20 \\
\hline
\end{tabular}

\footnotetext{
a $[\mathrm{M}],[\mathrm{RAFT}]$ and $[\mathrm{I}]$ are the feed concentration of monomer, PEG-macroRAFT agent, and initiator AIBN, respectively.

${ }^{b}$ Conversion is monomer conversion that was determined from the ${ }^{1} \mathrm{H}$ NMR spectra by comparison of the integrations of the vinyl proton peaks of the monomer and methyl protons in the polymer.

c Theoretical molecular weight was calculated by $\mathrm{Mn}=($ conversion $(\%) \times[\mathrm{M}] /[\mathrm{RAFT}] \times \mathrm{MW}($ monomer $))+\mathrm{MWRAFT}$.

d GPC molecular weights were determined by GPC (mobile phases, THF).

e PDI is polydispersity index.
} 
The GPC Shimadzu modular system comprised of an LC10ATVP Shimadzu solvent delivery system, a SIL-10ADVP Shimadzu autoinjector, a column set that consisted of a Phenomonex $5.0 \mu \mathrm{m}$ bead size guard column and four $5.0 \mu \mathrm{m}$ Phenomonex Phenogel columns $\left(500,10^{3}, 10^{4}\right.$, and $10^{6} \AA$ for the GPC using THF as mobile phase, and $500,10^{3}, 10^{4}$, and $10^{5} \AA$ for the GPC using DMAC as mobile phase), and a differential refractive-index detector. Temperature was kept constant at $40^{\circ} \mathrm{C}$ inside a CTO-10AC VP Shimadzu column oven. The columns were calibrated with commercial linear polystyrene standards ranging from 500 to $10^{6} \mathrm{~g} / \mathrm{mol}$.

\subsubsection{Dynamic light scattering (DLS)}

The hydrodynamic size of micelles was determined using a Malvern Zetasizer NaNo ZS Instrument (Malvern, USA) equipped with a $4 \mathrm{mV}$ He-Ne laser operating at $\lambda=633 \mathrm{~nm}$, an avalanche photodiode detector with high quantum efficiency, and an ALV/LSE-5003 multiple tau digital correlator electronics system. Samples were filtered prior to measurement and measured by scanning five times of 1.5 min duration without employing the dust filter function. The samples were prepared at $5 \mathrm{mg} / \mathrm{mL}$ concentration.

To make the polymer micelles for DLS measurements, PEG- $b$-PtBMA ( $\mathrm{Mn}=13,600$ by GPC, PDI $=1.10)(10 \mathrm{mg})$ was dissolved in $400 \mu \mathrm{L}$ of acetone, and dialyzed against water for three days. Milli-Q water was added to make the final solution volume to be $2 \mathrm{~mL}$.

\subsubsection{UV-vis spectrophotometry}

A double beam spectrophotometer (HITACHI U-2800) with a detection range from 190 to $800 \mathrm{~nm}$ and a photometric range of five absorbance units was used. Transmittance of PEG- $b$-PtBMA ( $\mathrm{Mn}=13,600$ by GPC, PDI $=1.10$ ) in various $\mathrm{pH}$ buffer solutions $(5 \mathrm{mg} / \mathrm{mL})$ was monitored at $650 \mathrm{~nm}$.

\subsubsection{Gel electrophoresis}

Gel electrophoresis of PEG- $b$-PCMA- $b$-siRNA conjugate was performed using 15\% TBE precast polyacrylamide gels (Bio-Rad). Samples (containing $0.025 \mathrm{nmol}$ siRNA) were loaded with $5 \mathrm{X}$ TBE urea loading buffer, and run at a constant voltage of $200 \mathrm{~V}$ for $30 \mathrm{~min}$ using $1 \mathrm{X}$ TBE buffer (tris-borate EDTA, pH 8.0). The gel was stained with $1 \mathrm{X}$ gel red in $100 \mathrm{mM} \mathrm{NaCl}$ solution for $30 \mathrm{~min}$. To demonstrate the release of PCMA- $b$-siRNA and siRNA segments from the modular conjugate under acidic and reductive conditions, the conjugate samples were incubated with $2 \mu \mathrm{L}$ of acetic acid buffer solution ( $\mathrm{pH} 2.2$ ) or $2 \mu \mathrm{L}$ of $10 \mathrm{mM}$ DTT for $4 \mathrm{~h}$ respectively, and then analyzed by gel electrophoresis.

\section{Results and discussion}

\subsection{Synthesis of acid-labile PEG-macroRAFT agent $\mathbf{3}$}

A new macromolecular RAFT agent with an acid-labile group was synthesized as shown in Scheme 1 . The cyclic acetal was chosen as an acid-labile group in the macroRAFT agent. Because acetals can easily be formed using a variety of hydroxyl groups including primary, secondary, tertiary, and syn-1,2- and -1,3-diols, and more importantly the rate of acid-catalyzed hydrolysis can be tailored diversely by varying the structure of the acetal [50-54].

First, precursor 1 was synthesized by an esterification reaction between PEG and formyl benzoic acid in the presence of DCC and DMAP. The integration ratio of phenyl group (7.92, $8.25 \mathrm{ppm})$, methylene group adjacent to ester (4.5 ppm), and methylene group in PEG (3.62-3.85 ppm, $450 \mathrm{H}$ ) of 2:2:2:450 (Fig. S1 in the Supporting Information), well-matched with the targeted structure, confirmed the successful synthesis of pure precursor $\mathbf{1}$. The following acetal reaction that was performed with tHEM under anhydrous conditions yielded precursor $\mathbf{2}$ bearing an acid-labile bond. From the ${ }^{1} \mathrm{H}$ NMR (Fig. S2 in the Supporting Information), the appearance of the acetal signal at $5.5 \mathrm{ppm}$ and the complete disappearance of the benzaldehyde signal at $10.2 \mathrm{ppm}$, indicated that the precursor 2 was obtained successfully. Precursor 2, could then be reacted readily with CPADB by an esterification reaction without any degradation of the thiocarbonylthio moiety and acetal group using a carefully optimized molar ratio of DCC and CPADB, 0.95:1. In ${ }^{1} \mathrm{H}$ NMR spectrum (Fig. 1A), the benzaldehyde signal at $10.05 \mathrm{ppm}$ could not been observed indicating that no hydrolysis of acetal group took place. Analysis by ${ }^{13} \mathrm{C}$ NMR also confirmed the successful synthesis of the expected PEG-macroRAFT agent structure (Fig. 1B). However, from the integration ratio of the phenyl group in CPADB and phenyl group adjacent to PEG chain, there was still a trace amount of unreacted precursor 2 left, although three times precipitation in cold diethyl ether was performed. Considering that the presence of the precursor $\mathbf{2}$ had no effect on the RAFT polymerization, and it could be easily removed by dialysis after polymerization (vide infra), no further purification was performed for the PEG-macroRAFT agent 3.

\subsection{Synthesis of block copolymers via RAFT polymerization}

The new PEG-macroRAFT agent 3, containing an acidlabile acetal group, was employed to mediate the chainextension copolymerizations. Various monomers (methyl methacrylate (MMA), tert-butyl methacrylate (tBMA), poly(ethylene glycol) methyl ether acrylate (PEG-A) and cholesterol methacrylate (CMA), were employed to test the new RAFT agent utility in controlling the polymerizations. A number of polymerizations were performed varying the ratio of the monomer, RAFT agent, and initiator concentration as summarized in Table 1 . The direct proportionality of [monomer]/[RAFT agent] ratio with the Mn of the polymers and the low PDI values indicated that the polymerizations were controlled by PEG-macroRAFT agent 3. The GPC analyses traces of the MMA, CMA, and PEG-A copolymerizations before purification are shown in Fig. S3 in Supporting Information.

To further assess the control ability of the PEG-macroRAFT agent, a kinetic study was undertaken for polymerization of t-BMA. An initial [tBMA]/[RAFT]/[AIBN] ratio of 300:1:0.2 was used. The GPC chromatograms (Fig. 2A) of the polymerization mixtures showed clear shifts with 
(A)<smiles>COC[C@H](O)COCCCOCCOC(=O)c1ccc(C=O)cc1</smiles><smiles>COCCOC(=O)c1ccc(C2OCC(C)(CO)CO2)cc1</smiles>

2

CPADB

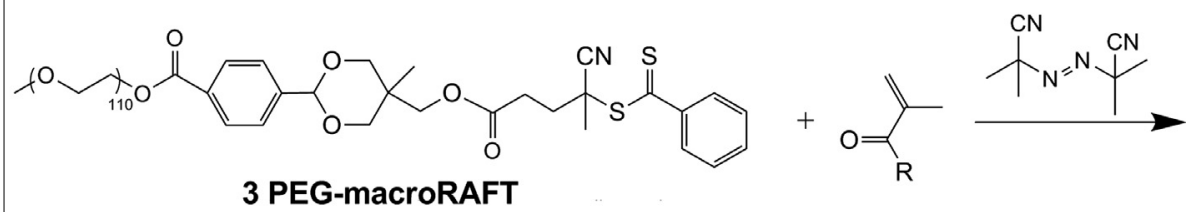

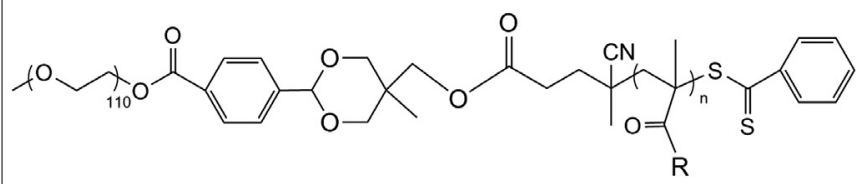

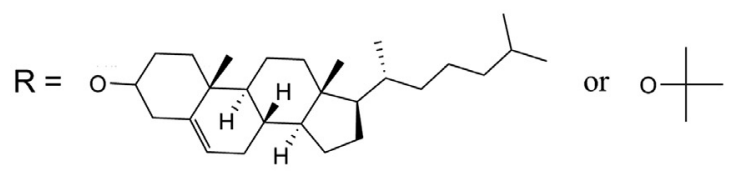

(B)

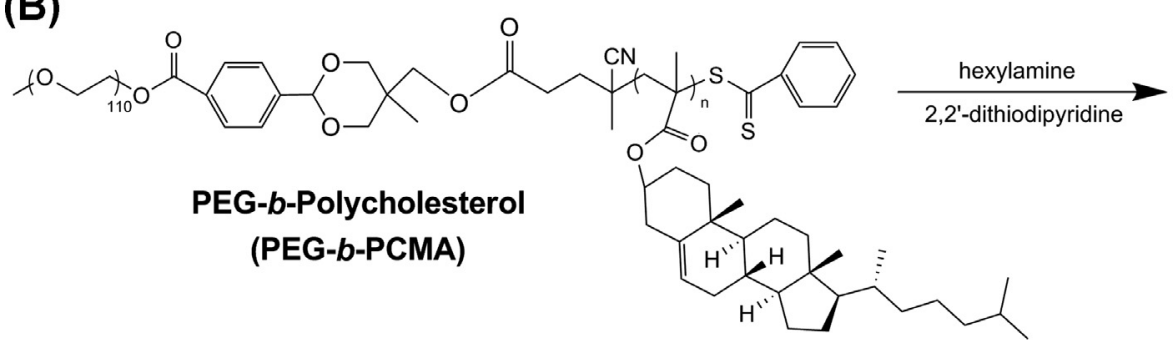

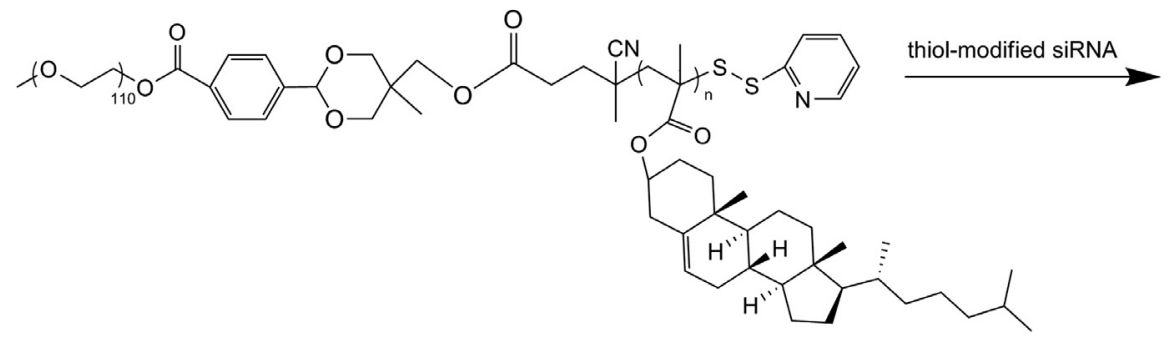

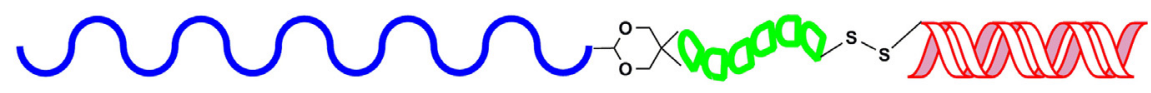

PEG-b-PCMA-siRNA

Scheme 1. Synthesis of the acid-labile PEG-macroRAFT agent and block copolymers (A), and the conjugation of siRNA (B).

increasing polymerization times, indicating the successful synthesis of the block copolymers. The low molecular weight trace observed consistently in each GPC trace was due to the existence of the unreacted precursor $\mathbf{2}$ in the initial PEG-macroRAFT agent. This was completely removed after purification by dialyzing against basic water containing $0.01 \%$ (V\%) TEA (Fig. S4 in the Supporting Information). In addition, linearity of the pseudo-first order kinetic plot (Fig. 2B) was indicative of a constant radical concentration. The molecular weight and PDI versus conversion plot 

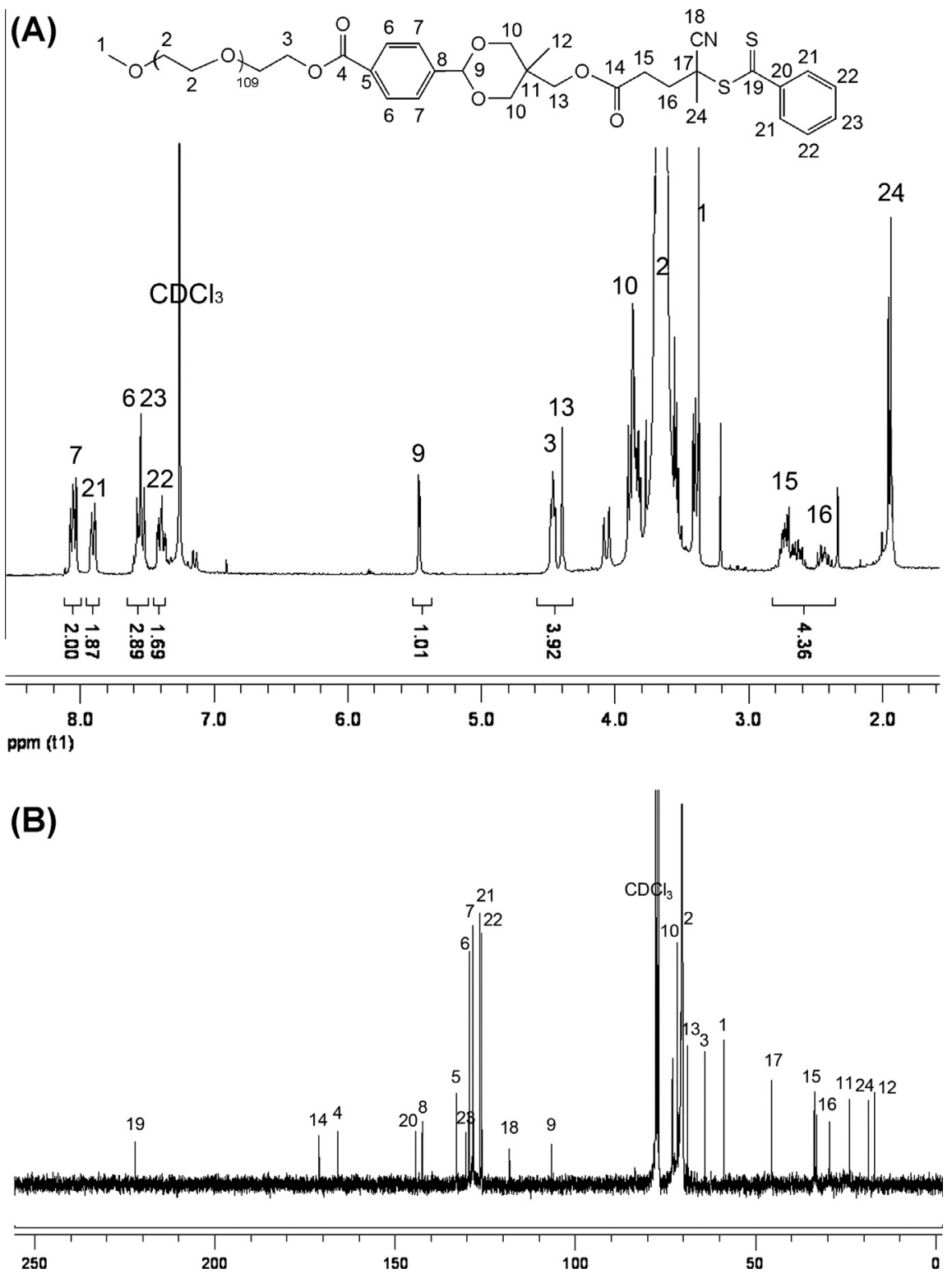

Fig. 1. ${ }^{1} \mathrm{H}$ NMR (A) and ${ }^{13} \mathrm{C}$ NMR (B) $\left(300 \mathrm{MHz}, \mathrm{CDCl}_{3}\right)$ spectra of purified PEG-macroRAFT agent 3.

(Fig. 2C) showed that the molecular weight increased linearly with conversion. As the reaction proceeded, the molecular weight distributions remained narrow $(\mathrm{PDI} \leqslant 1.20)$. Overall the polymerization results demonstrated that the new RAFT agent was able to control the chain extension polymerization.

\subsection{Determination of the polymer hydrolysis}

The acid-labile dePEGylation behavior of PEG- $b$-PtBMA ( $M n=13,600$ by GPC, PDI $=1.10)$ was investigated first by GPC. The GPC traces before and after hydrolysis are shown in Fig. 3. Chromatogram A shows the PEG- $b$-PtBMA before hydrolysis, and chromatogram $B$ shows the same polymer after incubating in acetic acid solution ( $\mathrm{pH} \mathrm{2.2)} \mathrm{for} 24 \mathrm{~h}$ at $37^{\circ} \mathrm{C}$. While the Mn of the polymer before hydrolysis was $13600 \mathrm{~g} / \mathrm{mol}$, two traces (Mn 7700 and $6100 \mathrm{~g} / \mathrm{mol}$ ) were obtained after incubation in acidic solution. The Mn of the traces after hydrolysis was in good agreement with the $\mathrm{Mn}$ of the copolymer before the hydrolysis. The retention time of the modified PEG (precursor 2) is the same with that of the longer elution time trace in chromatogram $\mathrm{b}$, which indicated that the hydrolysis of the copolymer took place at the acetal position, and the two traces in the chromatogram could be ascribed to PtBMA and the modified PEG (precursor 2).

The pH-dependent hydrolysis behavior of the copolymer was further confirmed by UV-vis spectroscopy. Since the block copolymers synthesized with tBMA, MMA and CMA have an amphiphilic character, they should be able 

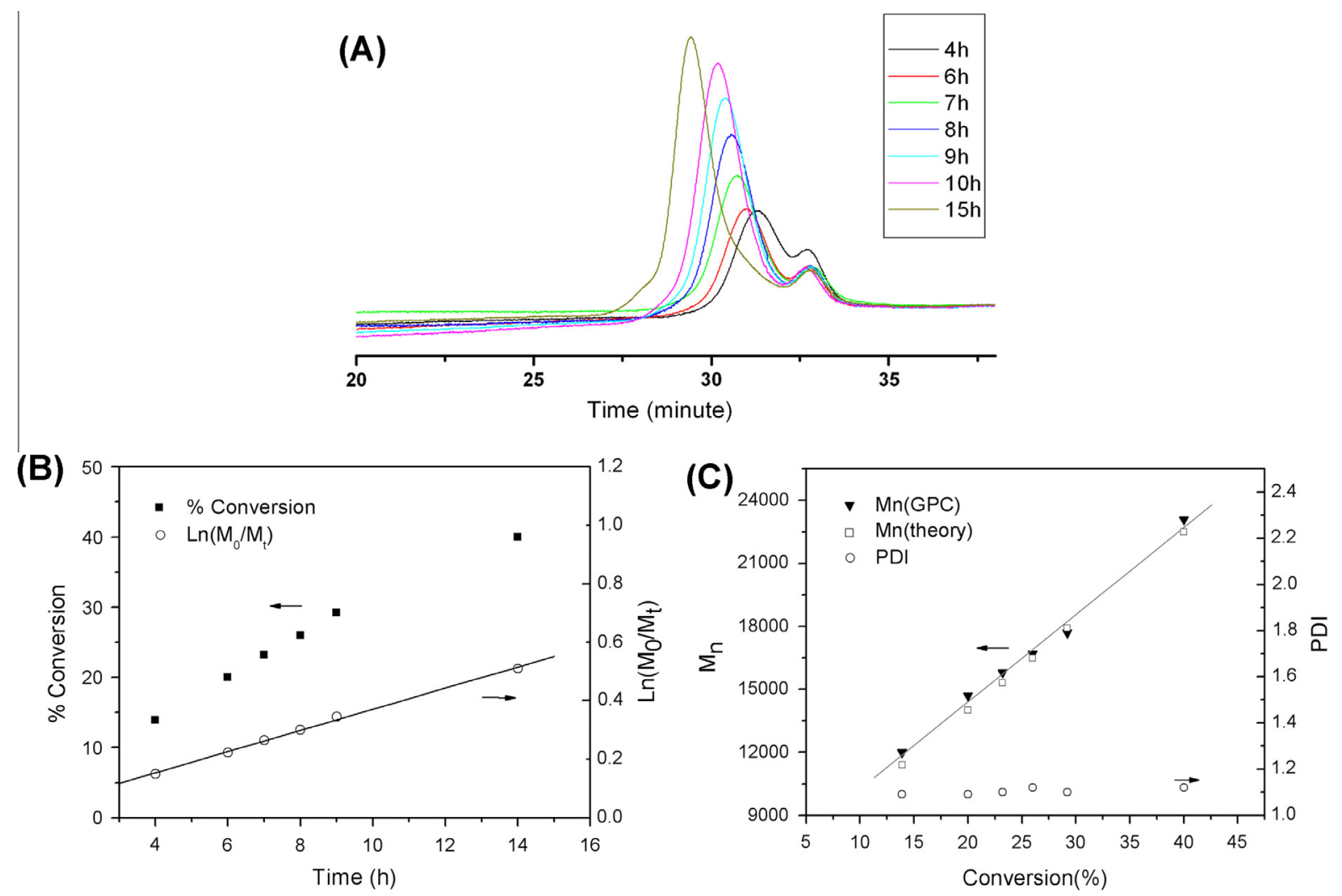

Fig. 2. RAFT polymerization of tert-butyl methacrylate (tBMA) using PEG-macroRAFT agent 3 in acetonitrile at $65{ }^{\circ} \mathrm{C}$. $[\mathrm{tBMA}]_{0} /[\mathrm{RAFT}]_{0} /[\mathrm{AIBN}]_{0}=300 / 1 / 0.2$, $[\mathrm{tBMA}]_{0}=1.0 \mathrm{~mol} / \mathrm{L} ;(\mathrm{A}) \mathrm{GPC}$ traces; (B) kinetics plot; (C) evolution of the number average molecular weight (Mn) and polydispersity index (PDI) versus conversion. The experimental molecular weight was measured by GPC calibrated with polystyrene standards using an RI detector.

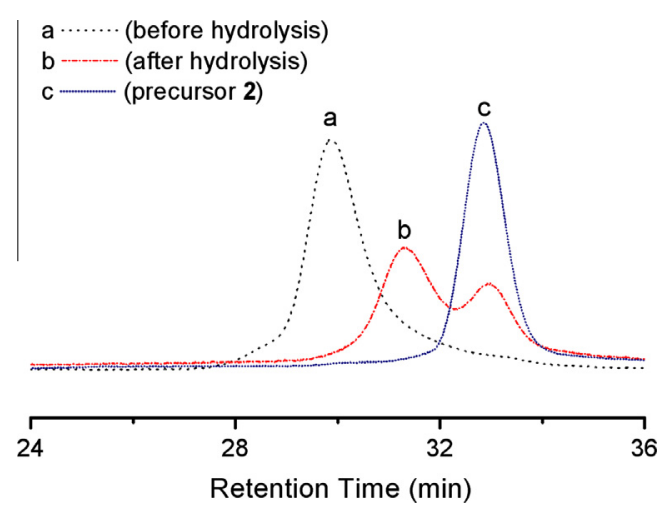

Fig. 3. GPC traces of PEG- $b$-PtBMA before (a) and after (b) hydrolysis, and the precursor 2 (c).

to form micelles in aqueous solutions at optimized conditions. Amphiphilic block copolymer micelles are useful tools for various drug delivery strategies. They are usually designed to be triggered to disassemble into their unimers or undergo complete degradation after delivering their therapeutic cargo. Micelles to be formed from acid-cleavable modular amphiphilic block copolymers would enable the disassembly of the structures at acidic environments. PEG- $b$-PtBMA $(M n=13,600$ by GPC, PDI $=1.10)$ in water $(5 \mathrm{mg} / \mathrm{mL}$ ) formed micelles as confirmed by DLS (data not

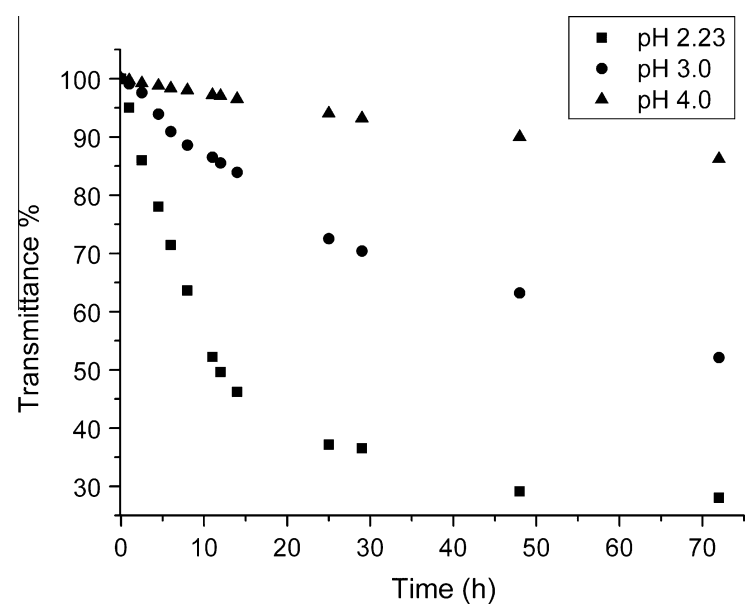

Fig. 4. UV-vis spectrometric measurements of PEG-b-PtBMA solution, at pH $2.2(\square)$, pH $3.0(\bullet)$ and $\mathrm{pH} 4.0(\boldsymbol{\Delta})$.

shown). The hydrodynamic diameter of the micelles in water was approximately $30 \mathrm{~nm}(\mathrm{PDI}=0.143$ ). The micelle solutions at different pHs were investigated by measuring the transmittance of the solutions using a UV-vis spectrometer (Fig. 4). The obvious decrease of the transmittance at $\mathrm{pH} 2$ with time, was attributed to the 
disappearance of micelles due to the hydrolysis of the acetal bond in the copolymer, leading to dePEGylation of the copolymers and subsequent separation of water-insoluble PtBMA block from aqueous solution.

After initial verification of the hydrolysis behavior of the modular block copolymers by GPC and UV-vis spectrometry, a more detailed study of the hydrolysis rate was undertaken by ${ }^{1} \mathrm{H}$ NMR. The precursor 2 which has better water solubility than the block copolymers was used in these experiments. ${ }^{1} \mathrm{H}$ NMR signals of precursor 2 in acidic solutions were recorded at predetermined time intervals in various $\mathrm{pH} \mathrm{D}_{2} \mathrm{O}$ solutions at $37^{\circ} \mathrm{C}$. As seen in Fig. 5A, with increasing reaction times, the hydrolysis can be clearly monitored by the appearance of the aldehyde proton signal at $10.05 \mathrm{ppm}$ with increasing intensity. Also, the signals of phenyl group after hydrolysis could be observed at 7.9 and $8.2 \mathrm{ppm}$. The hydrolysis percentage was calculated based on the integration ratio between the phenyl group at 7.6 ppm and total phenyl group peaks at 7.5$8.3 \mathrm{ppm}$. By plotting hydrolysis percentage versus time (Fig. 5B), the half-life of the acetal group in the polymer were deduced about $70 \mathrm{~min}$ at $\mathrm{pH} 2.2$ and $92 \mathrm{~h}$ at $\mathrm{pH} 4.0$.

\subsection{Modular PEG-b-PCMA-b-siRNA conjugates}

To further demonstrate the potential use of acid-reversible modular copolymer structure, a thiol-modified siRNA was conjugated to PEG- $b$-PCMA block copolymer synthe- sized using the new macroRAFT agent. A low molecular weight copolymer PEG- $b$-PCMA ( $\mathrm{Mn}=6442$ by ${ }^{1} \mathrm{H}$ NMR, $\mathrm{Mn}=7200$ by GPC, PDI 1.12) was used in these experiments to minimize the steric hindrance effects during the end-group conjugation of the copolymer with siRNA.

The ${ }^{1} \mathrm{H}$ NMR spectrum of the polymer PEG- $b$-PCMA is given in Fig. 6A. The proton signals of the phenyl group adjacent to PEG ( $\delta=8.05$ and $7.55 \mathrm{ppm}$ ), the phenyl group adjacent to thiocarbonylthio ( $\delta=7.8,7.5$ and $7.35 \mathrm{ppm}$ ), and vinyl group in cholesterol ( $\delta=5.35 \mathrm{ppm})$ are all clearly observed. Moreover, the integration ratio of the proton signal of the phenyl group adjacent to PEG $(\delta=8.05 \mathrm{ppm})$ and the acetal group ( $\delta=5.5 \mathrm{ppm}$ ) of $2: 1$, and the absence of benzaldehyde signal observed at $10.5 \mathrm{ppm}$ indicated that the acetal group was maintained during the polymerization.

The thiocarbonylthio end group of the polymers synthesized by RAFT polymerization can be easily functionalized with pyridyl disulfide group by aminolysis using an amine compound and 2,2'-dithiodipyridine (DTP) together to yield stable pyridyl disulfide (PDS)-functionalized polymers [38-40,55,56]. Following this strategy, $\omega$-pyridyl disulfide-functional PEG- $b$-PCMA was obtained by aminolyzing the copolymer in the presence of hexylamine and DTP. ${ }^{1} \mathrm{H}$ NMR spectrum of the purified polymer (Fig. 6B) confirmed the presence of the pyridyl disulfide group on the polymer chains, as evidenced by the existence of new signals at 8.4, 7.65 and $7.02 \mathrm{ppm}$ which were ascribed to
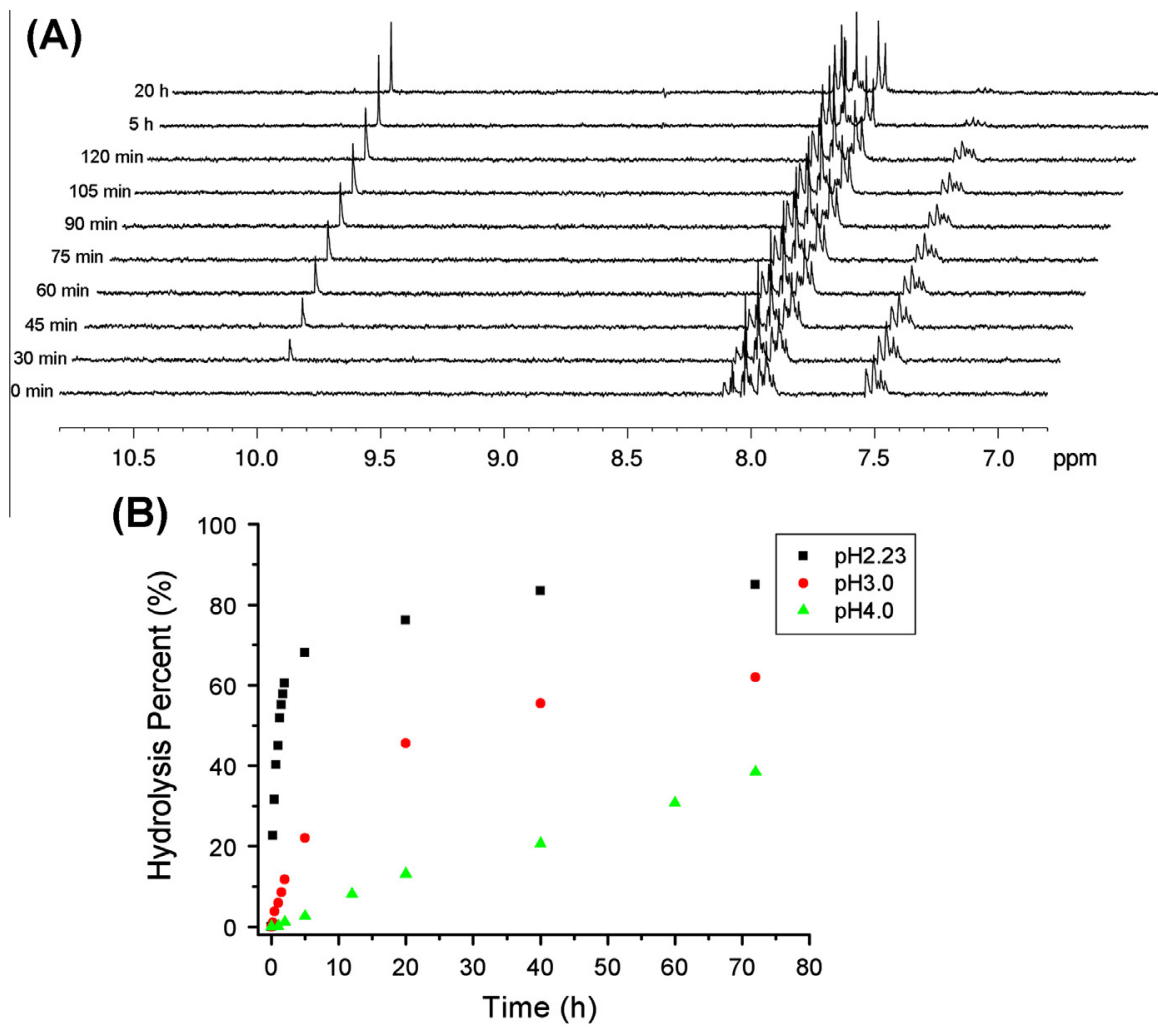

Fig. 5. The hydrolysis kinetics of acetal group in precursor 2 , determined at pH $2.2,3.0$ and 4.0 , at $37{ }^{\circ} \mathrm{C}$. (A) ${ }^{1} \mathrm{H}$ NMR spectrum at pH 2.2 , (for the spectra at $\mathrm{pH} 3.0$ and 4.0, see Fig. S5 in the Supporting Information) and (B) the hydrolysis percentages at various pHs based on the ${ }^{1} \mathrm{H}$ NMR results. 

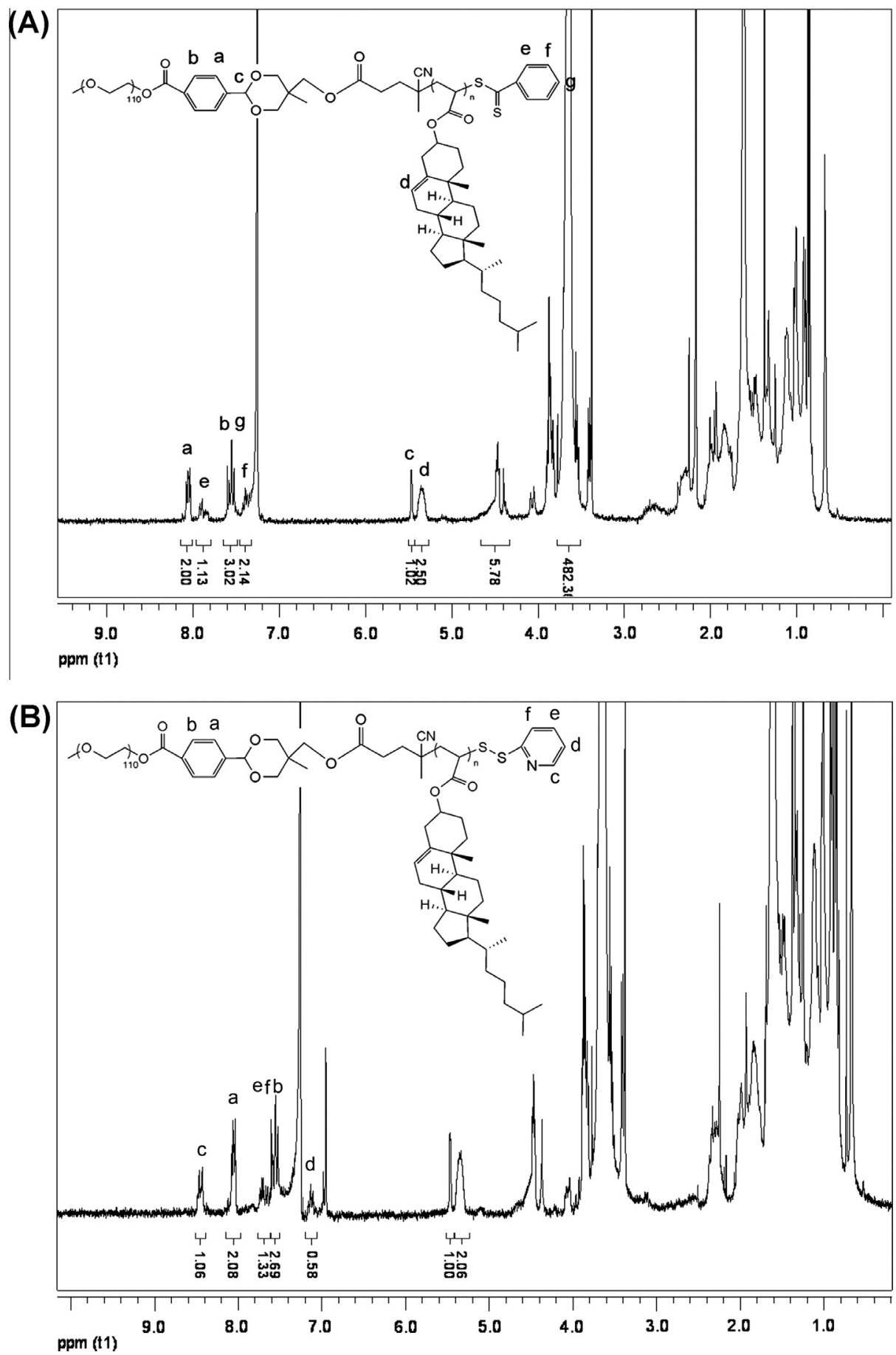

Fig. 6. ${ }^{1} \mathrm{H}$ NMR spectrum $\left(\mathrm{CDCl}_{3}\right.$ ) (A) of purified PEG-b-PCMA (Mn determined by ${ }^{1} \mathrm{H}$ NMR, $6442 \mathrm{~g} / \mathrm{mol}$; Mn determined by GPC, $7200 \mathrm{~g} / \mathrm{mol}$; and PDI, 1.12 ), and (B) after functionalizing the $\omega$-end group of the polymer with a pyridyl disulfide group.

the pyridyl protons. Subsequently, a $3^{\prime}$-antisense-thiol modified siRNA $[57,58]$ was conjugated to $\omega$-pyridyl disulfide-functional PEG- $b$-PCMA. The final modular conjugate, PEG- $b$-PCMA- $b$-siRNA contained an acid-cleavable acetal bond between the PEG and PCMA segments and a reducible disulfide bond between the PCMA and siRNA segments. The modular conjugate was expected to release
PCMA- $b$-siRNA segment under acidic conditions and siRNA under reductive conditions. Here it should be noted that under acidic conditions the release of siRNA together with a cellular membrane-destabilizing block such as PCMA [48] would be desirable for trafficking siRNA to cytosol from endocytic compartments such as endosomes or lysosomes. Subsequent to the release of the 


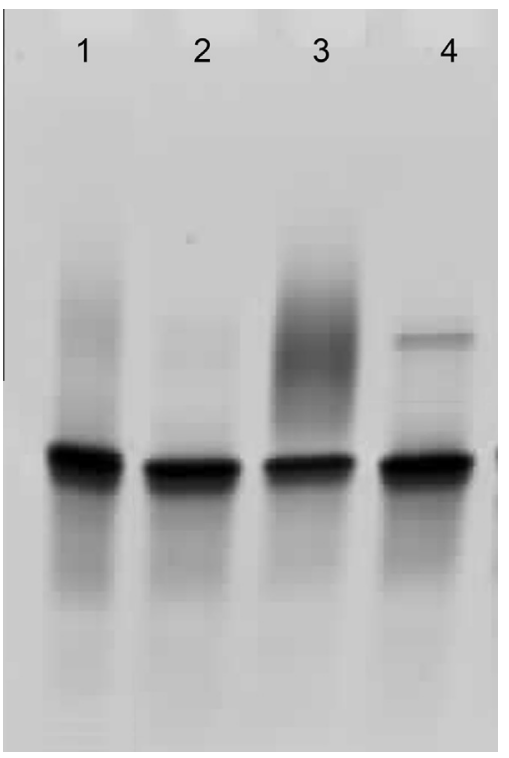

Fig. 7. Polyacrylamide gel electrophoresis of the siRNA-PEG- $b$-PCMA conjugates. Lanes 1 and 2: PEG- $b$-PCMA- $b$-siRNA after incubation in acidic and reducing conditions respectively, lane 3 PEG- $b$-PCMA- $b$-siRNA; lane 4: free siRNA.

membrane-destabilizing block-siRNA conjugate, siRNA is expected to be released from the membrane destabilizing block in the reducing environment of cytosol. The slow hydrolysis kinetic of the copolymers prepared by the new macroRAFT agent 3, presented in this study, clearly does not offer the desired release profile for cytoplasmic delivery siRNA. However, following the RAFT polymerization-based strategy reported in this study, it is possible to generate a variety of macroRAFT agents containing acetal or ketal bonds with faster hydrolysis kinetics suitable for endocytic pathway as the hydrolysis kinetics of acetals and ketals can be well-controlled by the substituent groups [50,51].

The acid and thiol labile reversibility of PEG- $b$-PCMA- $b$ siRNA was investigated using polyacrylamide gel electrophoresis (PAGE) (Fig. 7). After conjugation of siRNA with the diblock copolymer, an obvious shift to higher molecular weight (lane 3 ) was observed compared with the free siRNA (lane 4). The release of PCMA- $b$-siRNA and siRNA in acidic and reductive conditions, respectively, was confirmed by the disappearance of the higher molecular weight band in the gel. It should be noted that after acidcatalyzed hydrolysis, the PEG chain $(\mathrm{Mn}=5000 \mathrm{~g} / \mathrm{mol})$ was removed from the conjugate, leaving the PCMA (Mn $1440 \mathrm{~g} / \mathrm{mol}$ ) conjugated siRNA, PCMA-b-siRNA (Mn $18,925 \mathrm{~g} / \mathrm{mol}$ ), which has a molecular weight very close to the free siRNA $(17,485 \mathrm{~g} / \mathrm{mol})$, as observed in lane 1 .

\section{Conclusions}

A new strategy which is based on the use of an acidhydrolyzable PEG macroRAFT agent to prepare block copolymers and their bioconjugates has been outlined. This new strategy provides a versatile, RAFT polymerization- based route to $\mathrm{pH}$-labile dynamic drug/gene carriers adopting “dePEGylation" strategy.

\section{Acknowledgments}

The authors acknowledge the Australian Research Council (ARC) for funding (DP 0770818), the Centre for Advanced Macromolecular Design, School of Chemical Sciences and Engineering at The University of New South Wales for laboratory facilities and gel permeation chromatography measurements.

\section{Appendix A. Supplementary material}

Supplementary data associated with this article can be found, in the online version, at http://dx.doi.org/10.1016/ j.eurpolymj.2013.03.036.

\section{References}

[1] Pack DW, Hoffman AS, Pun S, Stayton PS. Design and development of polymers for gene delivery. Nat Rev Drug Discov 2005;4(7):581-93.

[2] Bae Y, Nishiyama N, Fukushima S, Koyama H, Yasuhiro M, Kataoka K. Preparation and biological characterization of polymeric micelle drug carriers with intracellular pH-triggered drug release property: tumor permeability, controlled subcellular drug distribution, and enhanced in vivo antitumor efficacy. Bioconjug Chem 2005;16(1):122-30.

[3] Baigude H, Rana TM. Delivery of therapeutic RNAi by nanovehicles. Chembiochemistry 2009;10(15):2449-54.

[4] Benoit DSW, Henry SM, Shubin AD, Hoffman AS, Stayton PS. pHresponsive polymeric siRNA carriers sensitize multidrug resistant ovarian cancer cells to doxorubicin via knockdown of polo-like kinase 1. Mol Pharmaceut 2010;7(2):442-55.

[5] Chan Y, Bulmus V, Zareie MH, Byrne FL, Barner L, Kavallaris M. Acidcleavable polymeric core-shell particles for delivery of hydrophobic drugs. J Control Release 2006;115(2):197-207.

[6] Chan Y, Wong T, Byrne F, Kavallaris M, Bulmus V. Acid-labile core cross-linked micelles for pH-triggered release of antitumor drugs. Biomacromolecules 2008;9(7):1826-36.

[7] Chen W, Meng FH, Li F, Ji SJ, Zhong ZY. pH-responsive biodegradable micelles based on acid-labile polycarbonate hydrophobe: synthesis and triggered drug release. Biomacromolecules 2009;10(7):1727-35.

[8] Ding CX, Gu JX, Qu XZ, Yang ZZ. Preparation of multifunctional drug carrier for tumor-specific uptake and enhanced intracellular delivery through the conjugation of weak acid labile linker. Bioconjug Chem 2009;20(6):1163-70.

[9] Du JZ, Sun TM, Song WJ, Wu J, Wang J. A tumor-acidity-activated charge-conversional nanogel as an intelligent vehicle for promoted tumoral-cell uptake and drug delivery. Angew Chem Int Ed 2010;49(21):3621-6.

[10] Kim SH, Jeong JH, Lee SH, Kim SW, Park TG. PEG conjugated VEGF siRNA for anti-angiogenic gene therapy. J Control Release 2006;116(2):123-9.

[11] Knorr V, Allmendinger L, Walker GF, Paintner FF, Wagner E. An acetal-based PEGylation reagent for $\mathrm{pH}$-sensitive shielding of DNA polyplexes. Bioconjug Chem 2007;18(4):1218-25.

[12] Mintzer MA, Simanek EE. Nonviral vectors for gene delivery. Chem Rev 2009;109(2):259-302.

[13] Mitsukami Y, Donovan MS, Lowe AB, McCormick CL. Water-soluble polymers. 81. Direct synthesis of hydrophilic styrenic-based homopolymers and block copolymers in aqueous solution via RAFT. Macromolecules 2001;34(7):2248-56.

[14] Morinaga H, Morikawa H, Wang YM, Sudo A, Endo T. Amphiphilic copolymer having acid-labile acetal in the side chain as a hydrophobe: controlled release of aldehyde by thermoresponsive aggregation-dissociation of polymer micelles. Macromolecules 2009;42(6):2229-35.

[15] Murthy N, Campbell J, Fausto N, Hoffman AS, Stayton PS. Bioinspired $\mathrm{pH}$-responsive polymers for the intracellular delivery of biomolecular drugs. Bioconjug Chem 2003;14(2):412-9. 
[16] Paramonov SE, Bachelder EM, Beaudette TT, Standley SM, Lee CC, Dashe J, et al. Fully acid-degradable biocompatible polyacetal microparticles for drug delivery. Bioconjug Chem 2008;19(4):911-9.

[17] Shi LJ, Berkland C. Acid-labile polyvinylamine micro- and nanogel capsules. Macromolecules 2007;40(13):4635-43.

[18] Bulmus V, Chan Y, Nguyen Q, Tran HL. Synthesis and characterization of degradable $\mathrm{p}$ (HEMA) microgels: use of acidlabile crosslinkers. Macromol Biosci 2007;7(4):446-55.

[19] Ganta S, Devalapally H, Shahiwala A, Amiji M. A review of stimuliresponsive nanocarriers for drug and gene delivery. J Control Release 2008;126(3):187-204.

[20] Gil ES, Hudson SM. Stimuli-reponsive polymers and their bioconjugates. Progr Polym Sci 2004;29(12):1173-222.

[21] Benoit DSW, Srinivasan S, Shubin AD, Stayton PS. Synthesis of folatefunctionalized RAFT polymers for targeted siRNA delivery. Biomacromolecules 2011;12(7):2708-14.

[22] Xu ZH, Gu WW, Chen LL, Gao Y, Zhang ZW, Li YP. A smart nanoassembly consisting of acid-labile vinyl ether PEG-DOPE and protamine for gene delivery: preparation and in vitro transfection. Biomacromolecules 2008;9(11):3119-26.

[23] Engin K, Leeper DB, Cater JR, Thistlethwaite AJ, Tupchong L Mcfarlane JD. Extracellular pH distribution in human tumors. Int J Hyperthermia 1995;11(2):211-6.

[24] Ojugo ASE, McSheehy PMJ, McIntyre DJO, McCoy C, Stubbs M, Leach $\mathrm{MO}$, et al. Measurement of the extracellular $\mathrm{pH}$ of solid tumours in mice by magnetic resonance spectroscopy: a comparison of exogenous F-19 and P-31 probes. Nmr Biomed 1999;12(8):495-504.

[25] Mellman I, Fuchs R, Helenius A. Acidification of the endocytic and exocytic pathways. Ann Rev Biochem 1986;55:663-700.

[26] Convertine AJ, Benoit DSW, Duvall CL, Hoffman AS, Stayton PS. Development of a novel endosomolytic diblock copolymer for siRNA delivery. J Control Release 2009;133(3):221-9.

[27] Hoffman AS, Bulmus V, Murthy N, Stayton PS. New "smart" polyelectrolyte drug carrier responsive to $\mathrm{pH}$ and glutathione for intracellular delivery of antisense oligonucleotides. Abstr Papers Am Chem Soc 2004;228. U357-U357.

[28] Johns RE, El-Sayed MEH, Bulmus V, Cuschieri J, Maier R, Hoffman AS, et al. Mechanistic analysis of macrophage response to IRAK-1 gene knockdown by a smart polymer-antisense oligonucleotide therapeutic. J Biomater Sci Polym Ed 2008;19(10):1333-46.

[29] Rozema DB, Lewis DL, Wakefield DH, Wong SC, Klein JJ, Roesch PL, et al. Dynamic PolyConjugates for targeted in vivo delivery of siRNA to hepatocytes. Proc Natl Acad Sci USA 2007;104(32):12982-7.

[30] Wolff JA, Rozema DB. Breaking the bonds: non-viral vectors become chemically dynamic. Mol Ther 2008;16(1):8-15.

[31] Sun HL, Guo BN, Li XQ, Cheng R, Meng FH, Liu HY, et al. Shellsheddable micelles based on dextran-SS-poly(epsilon-caprolactone) diblock copolymer for efficient intracellular release of doxorubicin. Biomacromolecules 2010;11(4):848-54.

[32] Gu JX, Cheng WP, Liu JG, Lo SY, Smith D, Qu XZ, et al. PH-triggered reversible "stealth" polycationic micelles. Biomacromolecules 2008;9(1):255-62.

[33] Romberg B, Hennink WE, Storm G. Sheddable coatings for longcirculating nanoparticles. Pharm Res 2008;25(1):55-71.

[34] Meyer M, Philipp A, Oskuee R, Schmidt C, Wagner E. Breathing life into polycations: functionalization with $\mathrm{pH}$-responsive endosomolytic peptides and polyethylene glycol enables siRNA delivery. J Am Chem Soc 2008;130(11). 3272-+.

[35] Meyer M, Dohmen C, Philipp A, Kiener D, Maiwald G, Scheu C, et al. Synthesis and biological evaluation of a bioresponsive and endosomolytic siRNA-polymer conjugate. Mol Pharmaceut 2009;6(3):752-62.

[36] Lin S, Du FS, Wang Y, Ji SP, Liang DH, Yu L, et al. An acid-labile block copolymer of PDMAEMA and PEG as potential carrier for intelligent gene delivery systems. Biomacromolecules 2008;9(1):109-15.

[37] Moad G, Rizzardo E, Thang S. Radical addition-fragmentation chemistry in polymer synthesis. Polymer 2008;49(5):1079-131.

[38] Boyer C, Bulmus V, Davis TP, Ladmiral V, Liu JQ Perrier S. Bioapplications of RAFT polymerization. Chem Rev 2009;109(11):5402-36.
[39] Boyer C, Bulmus V, Davis TP. Efficient usage of thiocarbonates for both the production and the biofunctionalization of polymers. Macromol Rapid Comm 2009;30(7):493-7.

[40] Boyer C, Liu J, Wong L, Tippett M, Bulmus V, Davis TP. Stability and utility of pyridyl disulfide functionality in RAFT and conventional radical polymerizations. J Polym Sci Part A Polym Chem 2008;46(21):7207-24.

[41] Huang X, Boyer C, Davis TP, Bulmus V. Synthesis of heterotelechelic polymers with affinity to glutathione-S-transferase and biotintagged proteins by RAFT polymerization and thiol-ene reactions. Polym Chem 2011;2(7):1505-12.

[42] Xu XW, Flores JD, McCormick CL. Reversible imine shell cross-linked micelles from aqueous RAFT-synthesized thermoresponsive triblock copolymers as potential nanocarriers for " $\mathrm{pH}$-Triggered" drug release. Macromolecules 2011;44(6):1327-34.

[43] Kellum MG, Smith AE, York SK, McCormick CL. Reversible interpolyelectrolyte shell cross-linked micelles from $\mathrm{pH} / \mathrm{salt}$ responsive diblock copolymers synthesized via RAFT in aqueous solutions. Macromolecules 2010;43(17):7033-40.

[44] Quek JY, Roth PJ, Evans RA, Davis TP, Lowe AB. Reversible additionfragmentation chain transfer synthesis of amidine-based, $\mathrm{CO}_{2}$ responsive homo and $\mathrm{AB}$ diblock (Co)polymers comprised of histamine and their gas-triggered self-assembly in water. J Polym Sci Part A Polym Chem 2013;51(2):394-404.

[45] Duong HTT, Hughes F, Sagnella S, Kavallaris M, Macmillan A, Whan $\mathrm{R}$, et al. Functionalizing biodegradable dextran scaffolds using living radical polymerization: new versatile nanoparticles for the delivery of therapeutic molecules. Mol Pharm 2012;9(11):3046-61

[46] Smith D, Holley AC, McCormick CL. RAFT-synthesized copolymers and conjugates designed for therapeutic delivery of iRNA. Polym Chem 2011;2(7):1428-41.

[47] Cheng C, Convertine AJ, Stayton PS, Bryers JD. Multifunctional triblock copolymers for intracellular messenger RNA delivery. Biomaterials 2012;33(28):6868-76.

[48] Sevimli S, Inci F, Zareie HM, Bulmus V. Well-defined cholesterol polymers with $\mathrm{pH}$-controlled membrane switching activity. Biomacromolecules 2012;13(10):3064-75.

[49] Sevimli S, Sagnella S, Kavallaris M, Bulmus V, Davis TP. Synthesis, self-assembly and stimuli responsive properties of cholesterol conjugated polymers. Polym Chem 2012;3(8):2057-69.

[50] Cordes EH, Bull HG. Mechanism and catalysis for hydrolysis of acetals, ketals, and ortho-esters. Chem Rev 1974;74(5):581-603.

[51] Gillies ER, Goodwin AP, Frechet JMJ. Acetals as pH-sensitive linkages for drug delivery. Bioconjug Chem 2004;15(6):1254-63.

[52] Heller J, Barr J, Ng SY, Abdellauoi KS, Gurny R. Poly(ortho esters): synthesis, characterization, properties and uses. Adv Drug Deliv Rev 2002;54(7):1015-39.

[53] Huang XN, Du FS, Liang DH, Lin SS, Li ZC. Stereochemical effect of trans/cis isomers on the aqueous solution properties of acid-labile thermoresponsive polymers. Macromolecules 2008;41(14):5433-40.

[54] Tang RP, Palumbo RN, Ji WH, Wang C. Poly(ortho ester amides): acid-labile temperature-responsive copolymers for potential biomedical applications. Biomacromolecules 2009;10(4):722-7.

[55] Boyer C, Liu JQ, Bulmus V, Davis TP. RAFT polymer end-group modification and chain coupling/conjugation via disulfide bonds. Aust J Chem 2009;62(8):830-47.

[56] Xu JT, Boyer C, Bulmus V, Davis TP. Synthesis of dendritic carbohydrate end-functional polymers via RAFT: versatile multifunctional precursors for bioconjugations. J Polym Sci Part A Polym Chem 2009;47(17):4302-13.

[57] Heredia KL, Nguyen TH, Chang CW, Bulmus V, Davis TP, Maynard HD. Reversible siRNA-polymer conjugates by RAFT polymerization. Chem Commun; 2008. p. 3245-7.

[58] Gunasekaran K, Nguyen TH, Maynard HD, Davis TP, Bulmus V. Conjugation of siRNA with comb-Type PEG enhances serum stability and gene silencing efficiency. Macromol Rapid Comm 2011;32(8):654-9. 